\title{
June 2002 through June 2004
}

\author{
C.C. Chancey, Editor \\ American Journal of Undergraduate Research \\ University of Northern lowa \\ Cedar Falls, lowa 50614-0150 USA
}

From June 2002, the first issue of this journal, through June 2004, AJUR published the research of 52 undergraduates. The geographical distribution of authors is illustrated in the figure below (with one dot per author). The variation and interdisciplinarity of their research topics makes a strict classification by topic difficult, but an attempt produces the following rough distribution:

$\begin{array}{ll}\text { Chemistry } & 9 \text { authors } \\ \text { Physics } & 8 \\ \text { Psychology } & 7 \\ \text { Engineering } & 7 \\ \text { Biology } & 6 \\ \text { Geology } & 4 \\ \text { Computer } & \\ \quad \text { Science } & 4\end{array}$

$\begin{array}{ll}\text { Statistics \& } & \\ \text { Mathematics } & 4 \\ \text { Sociology } & 2 \\ \text { Clinical Science } & 1\end{array}$

The current distribution of disciplinary editors in the Mideast US explains some of the geographical bunching, but one-third of our authors come from farther a field. The web edition of AJUR, limited though it is, likely explains the wider reach.

This issue shows the addition of AJUR's newest editor, Prof. Oluwole D. Makinde of the University of the North in Sovenga, South Africa. Professor Makinde joins AJUR as an Editor in Applied Mathematics. We are very pleased to welcome him and the expertise he brings to the iournal.

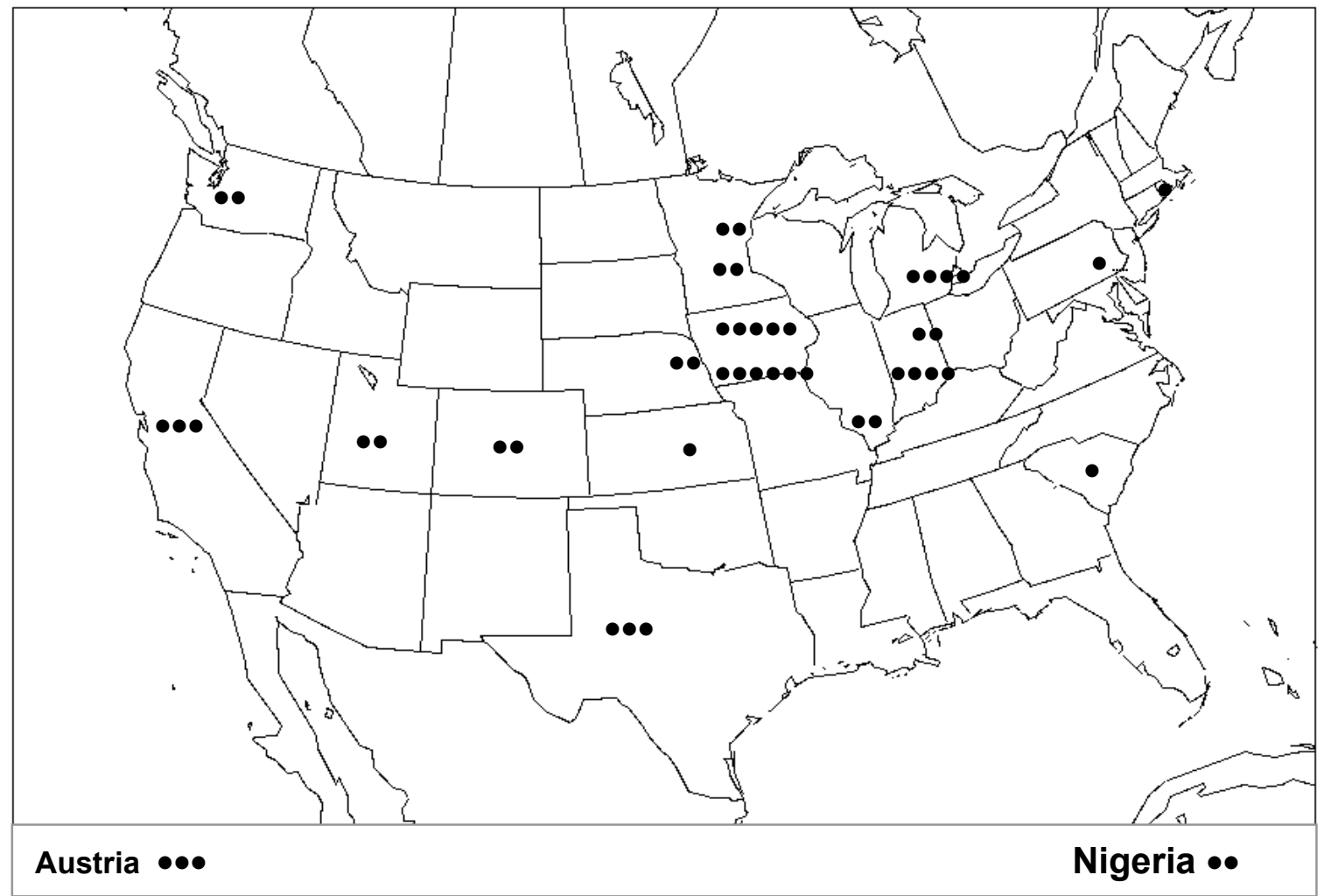

